\title{
Role of p38 MAPK in the Regulation of Apoptosis Signaling Induced by TNF- $\alpha$ in Differentiated PC12 Cells
}

\author{
Jung-Gyu Park ${ }^{\dagger, \#}$, Younjung Yuk ${ }^{\dagger}$, Hyewhen Rhim ${ }^{\ddagger}$, Seh-Yoon Yi ${ }^{\S}$ and Young Sook Yoo ${ }^{\dagger, *}$ \\ 'Bioanalysis and Biotransformation Research Center, \\ ${ }^{\ddagger}$ Biomedical Research Center, Korea Institute of Science and Technology, Seoul 130-650, \\ ${ }^{\S}$ Department of Applied Chemistry, Dongduk Women's University, Seoul 136-714, Korea
}

Received 31 October 2001, Accepted 11 December 2001

TNF- $\alpha$ elicits various responses including apoptosis, proliferation, and differentiation according to cell type. In neuronal PC12 cells, TNF- $\alpha$ induces moderate apoptosis while lipopolysarccaharide or trophic factor deprivation can potentiate apoptosis that is induced by TNF- $\alpha$. TNF- $\alpha$ initiates various signal transduction pathways leading to the activation of the caspase family, NF- $k B$, Jun $N$ terminal kinase, and p38 MAPK via the death domain that contains the TNF- $\alpha$ receptor. Inhibition of translation using cycloheximide greatly enhanced the apoptotic effect of TNF- $\alpha$. This implies that the induction of anti-apoptotic genes for survival by TNF- $\alpha$ may be able to protect PC12 cells from apoptosis. Accordingly, Bcl-2, an anti-apoptotic Bcl-2 family member, was highly expressed in response to TNF- $\alpha$. In this study, we examined the anti-apoptotic role of p38 MAPK that is activated by TNF- $\alpha$ in neuronal PC12 cells. The phosphorylation of $\mathbf{p 3 8}$ MAPK in response to TNF- $\alpha$ slowly increased and lasted several hours in the PC12 cell and DRG neuron. This prolonged and slow phosphorylation of p38 MAPK was distinct from other non-neuronal cells. The specific inhibitor of p38 MAPK, SB202190, significantly enhanced the apoptosis that was induced by TNF- $\alpha$ in PC12 cells. This indicates that the activation of p38 MAPK could protect PC12 cells from apoptosis since there is no known role of p38 MAPK in response to TNF- $\alpha$ in neuron. This discovery could be evidence for the neuroprotective role of the p38 MAPK.

Keywords: Apoptosis, Neuronal PC12 cells, p38 MAPK, SB202190, TNF- $\alpha$

*To whom correspondence should be addressed.

Tel : 82-2-958-5066; Fax: 82-2-958-5170

E-mail: ysyoo@kist.re.kr

"Present address: Biotech Research Institute I, LG Chemical Ltd., Taejon 305-380, Korea

\section{Introduction}

The tumor necrosis factor- $\alpha$ (TNF- $\alpha)$ is a pleiotropic cytokine, which elicits various cellular responses according to cell type through the TNF- $\alpha$ receptor (TNF-R). The TNF-R family includes the low-affinity nerve growth factor receptor, type I (p55) and type II TNF (p75) receptors. It is considered that $\mathrm{p} 55$ TNF-R is a major receptor type, which is responsible for various cellular effects of TNF- $\alpha$. These include apoptosis, cytokine production, proliferation, and differentiation according to the responding cell type.

In the nervous system, TNF- $\alpha$ has a diverse range of functions. In a developing brain TNF- $\alpha$ is expressed transiently and reduces the survival of serotonin neurons (Gendron et al., 1991; Jarskog et al., 1997). The expression of TNF- $\alpha$ in developing mice showed neurobehavioral alterations (Fiore et al., 1996). The overexpression of the wild-type murine or human TNF- $\alpha$ transgenes by resident astrocytes or neurons is sufficient to trigger a neurological disorder that is characterized by ataxia, seizures, and paresis with histopathological features of chronic CNS inflammation and white matter degeneration (Probert et al., 1997). TNF- $\alpha$ is normally absent in the adult brain; but, it can be induced by CNS injury, and cause subsequent neurological dysfunction (Lafortune et al., 1996; Tchelingerian et al., 1996; Knoblach et al., 1999; Dennis, 2001). It is also reported that the entry of TNF- $\alpha$ through the blood-brain barrier is increased after spinal cord injury (Pan et al., 1999). In summary, TNF- $\alpha$ regulates the CNS development and is involved in pathological conditions in the adult brain.

Type I TNF-R contains the death domain, which interacts with various signaling molecules. These include the TNFRassociated death domain protein (TRADD), TNF-R associated factor (TRAF), and Fas-associated death domain protein (FADD). Through these molecules, TNF- $\alpha$ can activate the Jun N-terminal Kinase (JNK), p38 mitogenactivated protein kinase (MAPK), NF- $\kappa \mathrm{B}$, and caspases.

The upstream activator of p38 MAPK and JNK is supposed 
to be a receptor-interacting protein (RIP) (Yuasa et al., 1998),

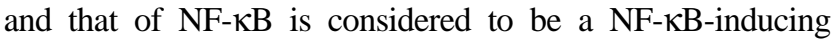
kinase (NIK) (Malinin et al., 1997; Koh et al., 2000). TRAF2 acts as an adaptor molecule for both RIP and NIK, which are responsible for the activation of $\mathrm{p} 38$ MAPK, JNK, and NF- $\mathrm{KB}$ (Arch et al., 1998; Baud et al., 1999). Interestingly, TNF- $\alpha$ can activate cytosolic phospholipase $\mathrm{A}_{2}\left(\mathrm{cPLA}_{2}\right)$ in a caspasedependent manner, and inhibition of this activation of $\mathrm{CPLA}_{2}$ prevents the apoptosis that is induced by TNF- $\alpha$ (Wissing et al., 1997).

Stimulation by a wide spectrum of stimuli (physicochemical stress and treatment with lipopolysaccharide or proinflammatory cytokines such as interleukin-1 and TNF- $\alpha$ ) activate p38 MAPK (Lee and Young, 1996). It has been reported that the activation of p38 MAPK protects cells from TNF- $\alpha$ mediated cytotoxicity in L929-cyt16 cells (Roulston et al., 1998). On the other hand, investigators have shown opposite results - TNF- $\alpha$ could induce apoptosis through the activation of p38 MAPK (Ichijo et al., 1997). In neuronal cells, however, the role of p38 MAPK activation by TNF- $\alpha$ in apoptosis has not been investigated. Furthermore, the activation mechanism of p38 MAPK by TNF- $\alpha$ is still unknown. The differentiated rat pheochromocytoma PC12 cell has been commonly used for the study of neuronal cell death because of its neuronal property (Greene and Tischler, 1976). In this study we examined the activation pathway of $\mathrm{p} 38$ MAPK in apoptosis that is induced by TNF- $\alpha$. We suggest that the activation of p38 MAPK can attenuate apoptosis that is induced by TNF- $\alpha$ in differentiated neuronal PC12 cells.

\section{Materials and Methods}

Cell culture and reagents PC12 cells were obtained from the American type cell collection (ATCC, Rockville, USA) and maintained in a RPMI1640 medium that was supplemented with $10 \%$ heat-inactivated fetal bovine serum (HI-FBS) (Life Technologies, Inc., Gaithersburg, USA). For differentiation, the cells were maintained in the presence of $100 \mathrm{ng} / \mathrm{ml}$ nerve growth factor (NGF) (Sigma, St. Louis, USA) for 7 days in RPMI1640 that contained $1 \%$ HI-FBS in calf-skin collagen-coated 60 -mm dish or 6-well plate (Choi et al., 2000).

Female Sprague-Dawley rats (100-150 g) were anesthetized with ether by inhalation, and killed by decapitation. Dorsal root ganglia (DRG) were dissected from all levels of the lumbar and sacral cord, incubated with $0.15 \%$ collagenase, then with $0.125 \%$ trypsin in $\mathrm{Ca}^{2+}$ - and $\mathrm{Mg}^{2+}$-free $N^{\prime}$-2-hydroxyehtylpiperazine- $N$ '-2-ethane sulfonic acid (HEPES) buffer solution at $37^{\circ} \mathrm{C}$. The DRG neurons were then mechanically dissociated with fire-polished Pasteur pipettes and plated on poly-L-lysine coated 24-well dishes. The cells were maintained in a Neurobasal ${ }^{\mathrm{TM}}$ medium (Life Technologies, Inc.) that was supplemented with B27 (Life Technologies, Inc.) and L-glutamine $2 \mathrm{mM}$ (Life Technologies, Inc.) under a humidified atmosphere of $95 \%$ air $/ 5 \% \mathrm{CO}_{2}$ at $37^{\circ} \mathrm{C}$.

The primer for $b c l-2, b a x$, and $\beta$-actin were from Life
Technologies, Inc. The CPLA $_{2}$ specific inhibitor arachidonyltrifluromethyl ketone $\left(\mathrm{AACOCF}_{3}\right)$ was from Biomol (Plymouth Meeting, USA). TNF- $\alpha$ was from R\&D Systems (Minneapolis, USA) and SB202190 was from Calbiochem (La Jolla, USA).

Western blot analysis The p38 MAPK and phosphorylated p38 MAPK were detected by a Western blot analysis. After treatment with an appropriate stimuli, the medium was aspirated, and the cell monolayers were solubilized in a SDS sample buffer $[62.5 \mathrm{mM}$ Tris-HCl (pH 6.8), 2\% w/v SDS, $10 \%$ glycerol, 50 mM DTT, $0.1 \%$ $\mathrm{w} / \mathrm{v}$ bromophenol blue]. The solubilized samples were sonicated for $10-15 \mathrm{~s}$ to shear DNA, and centrifuged at $10,000 \times \mathrm{g}$ for $15 \mathrm{~min}$. Proteins in the supernatant were separated by SDS/PAGE and transferred to nitrocellulose. After blocking, the membranes were incubated with an phospho-p38 MAPK specific polyclonal antibody (New England Biolab, Beverly, USA), phospho-p38 MAPK specific monoclonal antibody (kind gift from Dr. Rony Seger, WIS, Israel), p38 MAPK-specific antibody (Santa Cruz, Santa Cruz, USA), or Bcl-2 specific monoclonal antibody (Santa Cruz), according to the manufacturerís protocol. The membrane was then incubated with a horse redox peroxidase-conjugated secondary antibody, and binding was detected by enhanced chemiluminescence, as described by the manufacturer (ECL; Amersham, Buckinghamshire, UK).

Quantification of apoptosis For DNA staining, the cells were fixed with PBS that contained 4\% paraformaldehyde for $20 \mathrm{~min}$ at room temperature. Ten $\mu \mathrm{g} / \mathrm{ml}$ Hoechst 33285 (Calbiochem) in PBS was added to the cell monolayer. After $10 \mathrm{~min}$, the cells were washed with PBS and examined under UV illumination on a fluorescence microscope. The cells with condensed and fragmented nuclei were counted in randomly selected regions; the counts were made with no knowledge of the treatment history.

The assay of apoptosis was also performed using a Cell Death Detection ELISA Kit (Boehringer Mannheim, Germany).

\section{Results}

TNF- $\alpha$ induces moderate apoptosis in differentiated PC12 cells TNF- $\alpha$ induced apoptosis in differentiated PC12 cells in a dose dependent manner (Fig. 1a), but the intensity of apoptosis was moderate compared to the apoptosis that was induced by Fas-ligand (Fas-L) in other cell types (Roulston et al., 1998). Both Fas and p55 TNF-R contain the death domain and activate the caspase family in a protease cascade manner, which needs no expression of new proteins. Therefore, we postulated that TNF- $\alpha$ could also activate survival pathways, which lead to the attenuation of the death pathway that is mediated by the death domain and that the survival pathways may involve a new gene expression. If this postulation is true, then the blockade of the protein expression would enhance the cell death that is induced by TNF- $\alpha$ in PC12 cells. As expected, the results showed that the inhibition of the protein expression by cycloheximide greatly increased the apoptosis that was induced by TNF- $\alpha$ (Fig. 1b, TNF + CHX), compared 


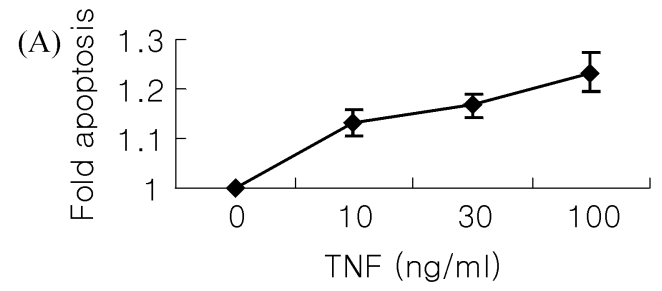

(B)

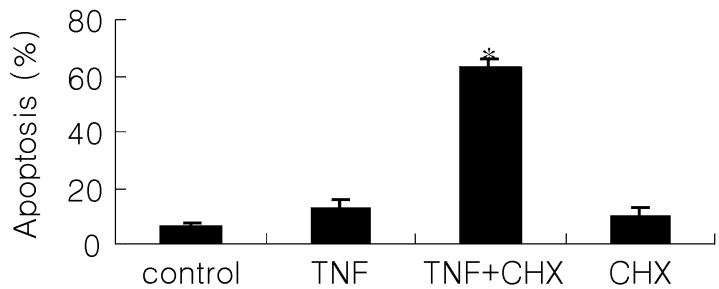

Fig. 1. TNF- $\alpha$ induces moderate apoptosis in PC12 cells. (A) Differentiated PC12 cells were incubated with TNF- $\alpha$ for $12 \mathrm{~h}$. The intensity of apoptosis was determined by measuring monoand oligo-nucleosomes in the cell lysates, using a Cell Death Detection ELISA Kit. Data are presented as means \pm S.E. of fold apoptosis with respect to untreated cells. (B) PC12 cells were incubated with the indicated agent (TNF $30 \mathrm{ng} / \mathrm{ml}$, cycloheximide (CHX) $5 \mu \mathrm{g} / \mathrm{ml}$ ) for $12 \mathrm{~h}$ and assayed for the apoptosis by nuclear staining, described in Experimental Procedures. Data are means \pm S.E. $* P<0.01$ versus control.

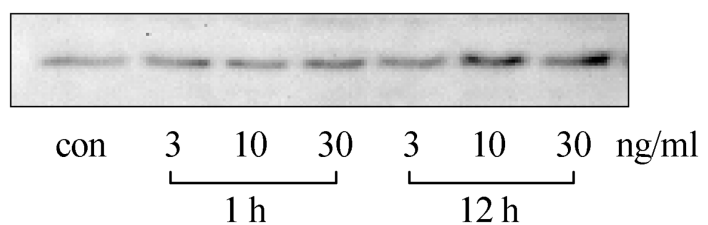

Fig. 2. The induction of bcl-2 in response to TNF- $\alpha$. Dose- and time-dependent expression of $b c l-2$ that was induced by TNF- $\alpha$ was determined by a Western blot analysis. Thirty micrograms of protein were loaded in each lane.

to the apoptosis level that was induced by TNF alone (Fig. 1b, TNF). Cycloheximide itself induced no significant apoptosis up to $12 \mathrm{~h}$ (Fig. 1b, CHX).

Accordingly, the expression of anti-apoptotic gene, bcl-2, also increased $12 \mathrm{~h}$ after the treatment of TNF- $\alpha$ in a dosedependent manner (Fig. 2).

p38 MAPK is activated in response to TNF- $\alpha$ The p38 MAPK and JNK are phosphorylated and activated in response to TNF- $\alpha$ in various cell types, including PC12 cells (Fig. 3, Modur et al., 1996; Roulston et al., 1998). It was reported that the activation of JNK and p38 MAPK, in response to TNF- $\alpha$, is very rapid. Also, the early activation of JNK and p38 MAPK usually appeared within 10 min and slowly decreased in the L929-cyt16 cells (Modur et al., 1996; Roulston et al., 1998). However, in the differentiated PC12 cells, the phosphorylation of p38 MAPK slowly increased up to $6 \mathrm{~h}$ after the treatment of TNF- $\alpha$ (Fig. 3). The phosphorylation pattern of p38 MAPK in our system was somewhat different

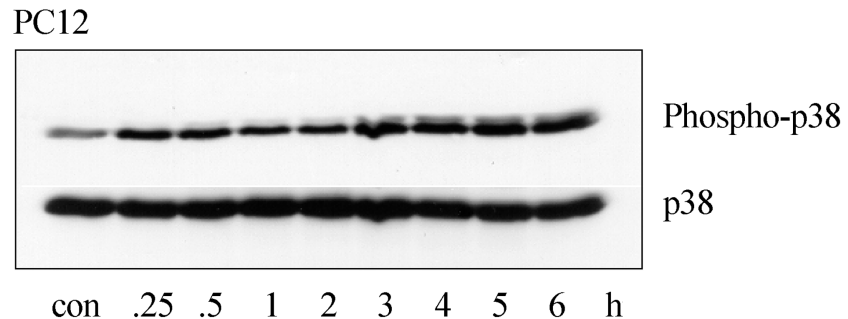

DRG neuron

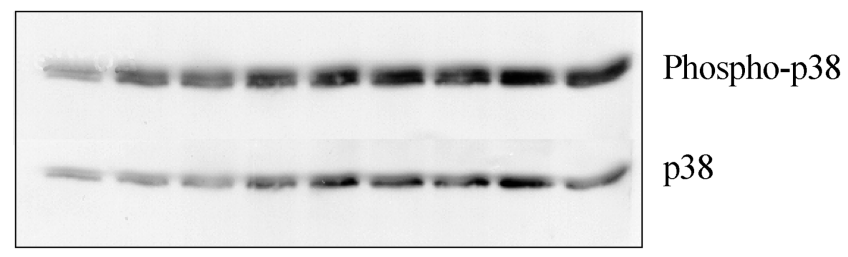

con $\begin{array}{llllllll}25 & .5 & 1 & 2 & 3 & 4 & 5 & 6 \mathrm{~h}\end{array}$

Fig. 3. Time course phosphorylation of p 38 MAPK in PC12 cell and DRG neuron in response to TNF- $\alpha$. Cells were treated with TNF- $\alpha(30 \mathrm{ng} / \mathrm{ml})$ for various durations. Western blotting was performed as indicated in Materials and Methods. Identical results were obtained in the other two experiments.

than that of others. To examine whether this slow increase in the phosphorylation of p38 MAPK in response to TNF- $\alpha$ was confined to PC12 cells, we also performed the same experiment in a primary dorsal root ganglia neuron. The phosphorylation pattern of the DRG neuron was exactly the same as in the PC12 cells (Fig. 3).

Activation of p38 MAPK partially prevents TNF- $\alpha$ induced apoptosis $\mathrm{In}$ order to investigate the role of $\mathrm{p} 38$ MAPK in the TNF- $\alpha$-induced apoptosis event in the neuronal systems, we used the p38 MAPK inhibitor SB202190 along with the TNF- $\alpha$ treatment to the differentiated PC12 cells (Lee et al., 1994; Cuenda et al., 1995). According to cell types and stimuli that induces apoptosis, the activation of p38 MAPK was reported to either contribute to apoptosis or protect the cells from the cell death (Roulston et al., 1998; Jun et al., 1999). In our experiment, SB202190 increased the TNF- $\alpha$-induced apoptosis in differentiated PC12 cells, compared to the increment of the apoptosis level between TNF alone (Fig. 4, TNF) and the SB202190 co-treatment group (Fig. 4, TNF + SB). SB202190 itself did not affect the viability of the cells (Fig. 4, SB). This indicated that p38 MAPK may act as an anti-apoptotic protein in response to TNF- $\alpha$ in differentiated PC12 cells. Until now, nothing has been known about the role of p38 MAPK in response to TNF$\alpha$ in neuronal cells. Therefore, this study is the first to report data regarding the function of the TNF- $\alpha$ activated $\mathrm{p} 38$ MAPK in neuronal cells.

In order to determine the significance of the relationship between the early and late phases of the phosphorylation of p38 MAPK in attenuating the cell death, which is induced by TNF- $\alpha$, we blocked the late phase activation of p38 MAPK by 


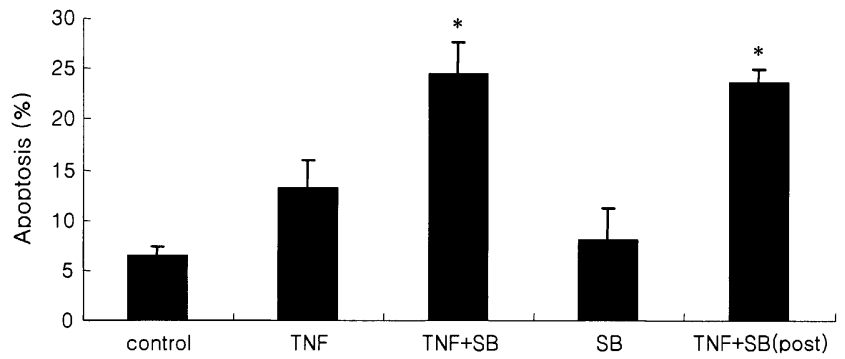

Fig. 4. Inhibitor of p38 MAPK, SB202190 enhanced the apoptosis induced by TNF- $\alpha$ in PC12 cells. Cells were treated with TNF- $\alpha(30 \mathrm{ng} / \mathrm{ml})$ and SB202190 $(10 \mu \mathrm{M})$ for $12 \mathrm{~h}$. The apoptotic cell was assayed by nuclear staining. In group $\mathrm{TNF}+\mathrm{SB}$ (post), SB202190 was treated $3 \mathrm{~h}$ after the TNF- $\alpha$ stimulus. Data are means \pm S.E. $* P<0.01$ versus control.

adding the inhibitor, SB202190, after a 3 hour-incubation in TNF- $\alpha$. As shown in Fig. 4, we found no significant difference in the apoptosis level between the two groups, $\mathrm{TNF}+\mathrm{SB}$ and $\mathrm{TNF}+\mathrm{SB}$ (post). From this result, it is apparent that the late phase of the p38 MAPK activation by TNF- $\alpha$ played an important role in preventing apoptosis in differentiated PC12 cells.

Activation of CPLA $_{2}$ suppresses the phosphorylation of p38 MAPK Reportedly, TNF- $\alpha$ can activate the $\mathrm{CPLA}_{2}$ that promotes cell death in breast carcinoma and fibrosarcoma cells (Wissing et al., 1997). But, it is not known how the activation of $\mathrm{cPLA}_{2}$ can promote cell death in response to TNF- $\alpha$. Since our results (Fig. 4) showed that the activation of p38 MAPK could protect PC12 cells from apoptosis, we hypothesized that the activation of $\mathrm{CPLA}_{2}$ could promote apoptosis by down-regulating the activity of p38 MAPK. In order to investigate the effect of the activation of $\mathrm{CPLA}_{2}$ on the activity of p38 MAPK in PC12 cells, we inactivated cPLA $_{2}$ with its specific inhibitor arachidonyltrifluromethyl ketone $\left(\mathrm{AACOCF}_{3}\right)$. The down-regulation of $\mathrm{CPLA}_{2}$ with $\mathrm{AACOCF}_{3}$ greatly enhanced the phosphorylation of p38 MAPK that is induced by TNF- $\alpha$ (Fig. 5). Based on these results, it is possible to conclude that the activation of $\mathrm{CPLA}_{2}$ suppresses the activation of p38 MAPK by a mechanism that is still unknown, thus delaying the activation of p38 MAPK; therefore, apoptosis may be promoted in response to TNF- $\alpha$.

\section{Discussion}

The PC12 cell is widely used in various types of neurochemical studies, and the neuronal cell death model, because of its neuronal property (Green, 1982). The PC12 cell can be reversibly differentiated into the neuronal cell by the prolonged treatment of NGF. The differentiated PC12 cell expresses many neuronal markers and enzymes that are specifically expressed in neurons (Shafer and Atchison, 1991). We examined apoptosis that is induced by TNF- $\alpha$ in this cell line. TNF- $\alpha$ is a pro-inflammatory cytokine that mediates the

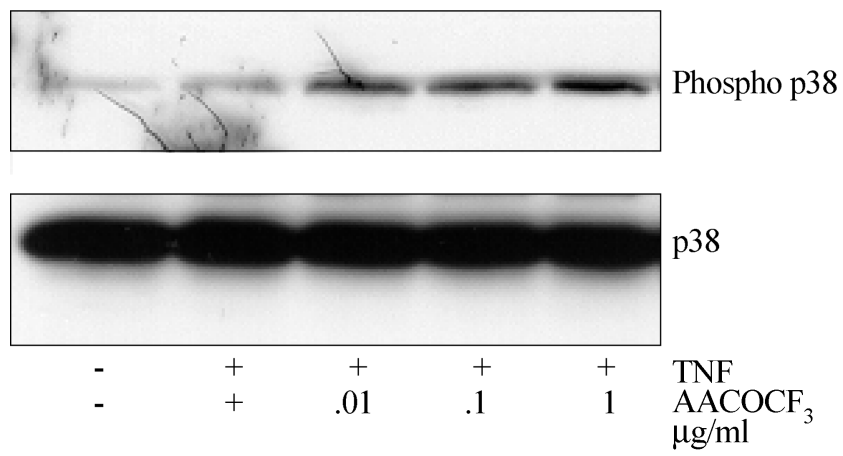

Fig. 5. The inhibitor of $\mathrm{cPLA}_{2}, \mathrm{AACOCF}_{3}$ enhanced the phosphorylation of p38 MAPK in response to TNF- $\alpha$. Cells were treated with $\mathrm{AACOCF}_{3}$ at indicated concentrations for $1 \mathrm{~h}$. The Western blotting for phopho-p38 MAPK was performed as indicated in Materials and Methods.

inflammatory response. In CNS, TNF- $\alpha$ is induced in the glial cells (Lafortune et al., 1996; Tchelingerian et al., 1996; Knoblach et al., 1999), and is also transported across the blood-brain barrier after injury (Pan et al., 1999). An exact knowledge of TNF- $\alpha$ is important, because it is the major cytokine that elicits the inflammatory process after CNS injury (Feuerstein et al., 1998; Knoblach et al., 1999).

In this study, we identified the activation of p38 MAPK in response to TNF- $\alpha$, and its role in differentiated PC12 cells. Surprisingly, the phosphorylation kinetics of p38 MAPK in response to TNF- $\alpha$ in the differentiated PC12 cells (Fig. 3) are different from other cell types (Roulston et al., 1998). Yuasa et al. (1998) demonstrated that the activation of p38 by TNF- $\alpha$ is mediated by RIP, which can be associated with TRAF2 through the death domain. It also activates MKK6, the direct activator of p38 MAPK. The slowly increased phosphorylation of p38 MAPK in our experiment (Fig. 3) did not coincide with this model, because these phosphorylation cascades that were initiated from the receptor activation were a more rapid process. These results imply that the activation of p38 MAPK in the differentiated PC12 cell may use different pathways, such as a signaling pathway through a second messenger, which accumulates by enzymatic activity.

Unlike Fas-L, the TNF- $\alpha$-mediated apoptosis was greatly enhanced by the inhibition of the transcription or translation in PC12 cells (Fig. 2), which was also shown by another investigator (Roulston et al., 1998). Therefore, a new gene expression was needed to protect the PC12 cells from apoptosis in response to TNF- $\alpha$. In hippocampal neurons, TNF- $\alpha$ protects the cells from hypoxia-induced cell death, and induces the anti-apoptotic protein Bcl-2 and Bcl-x expressions (Tamatani et al., 1999). In differentiated PC12 cells, Bcl-2 was also induced by TNF- $\alpha$ (Fig. 2). TNF- $\alpha$, therefore, activates both the death and survival pathways.

Interestingly, the activation of p38 MAPK shows two different actions with opposite manners, according to stimuli and cell types. To be more specific, the activation of $\mathrm{p} 38$ 
MAPK by the overexpression of Ask1 was shown to induce the apoptosis of the cell, while the activation by TNF- $\alpha$ was shown to protect the L929-cyt16 cell from apoptosis (Ichijo et al., 1997; Roulston et al., 1998). However, in neuronal cells, the role of p38 MAPK activation in apoptosis that was induced by TNF- $\alpha$ has not yet been reported. SB202190 is widely used as a p38 MAPK inhibitor (Lee et al., 1994). Using this inhibitor, we examined the effect of the activation of $\mathrm{p} 38$ MAPK in response to TNF- $\alpha$ in differentiated PC12 cells. Although SB202190 itself did not induce apoptosis in the differentiated PC12 cell, the apoptosis that was induced by TNF- $\alpha$ increased about 3-fold in the presence of SB202190. Collectively, these results show the delayed activation of $\mathrm{p} 38$ MAPK. It can be seen that the late activation of p38 MAPK after caspase activation may attenuate the apoptosis that is induced by TNF- $\alpha$. These results highlight the potential use of p38 MAPK as a protection against apoptosis, even after the apoptosis inducer has already been introduced into the system.

We have shown that the phosphorylation of p38 MAPK is regulated by $\mathrm{CPLA}_{2}$, which produces arachidonic acid (AA) by cleaving phospholipid. AA exerts many biological actions. These include the modulation of the activities of protein kinases and ion channels, inhibition of neurotransmitter uptake, and enhancement of synaptic transmission. AA also serves as a precursor of a variety of eicosanoids, which are formed by the oxidative metabolism of AA. The AA cascade is activated under several pathological conditions in the brain, such as ischemia and seizures. It also may be involved in irreversible tissue damage (Katsuki and Okuda, 1995). Our results present one possible mechanism for enhancing the neuronal cell death by AA through the regulation of p38 MAPK. However, how AA attenuates the phosphorylation of p38 MAPK is unknown.

In summary, our study demonstrated that the weak apoptotic activity of TNF- $\alpha$ in differentiated PC12 cells is due to the protective role of $\mathrm{p} 38$ MAPK that is activated by TNF$\alpha$. This activation of $\mathrm{p} 38$ was regulated by $\mathrm{CPLA}_{2}$, which was also activated by TNF- $\alpha$. Therefore, the inactivation of $\mathrm{cPLA}_{2}$ could be a possible therapeutic target in many neurodegenerative diseases that are mediated by TNF- $\alpha$.

Acknowledgments This work was supported in part by a grant from the Neurobiology Program (2N21510 \& 2N22780) to T.H. Oh, and a grant from the Life Phenomena \& Function Research Group (2N21590 \& 2N23080) to Y.S. Yoo from the Ministry of Science and Technology. The authors wish to thank Miss Bai for her helpful comments on this manuscript.

\section{References}

Arch, R. H., Gedrich, R. W. and Thompson, C. B. (1998) Tumor necrosis factor receptor-associated factors (TRAFs)--a family of adapter proteins that regulates life and death. Genes Dev. 12, 2821-2830.

Baud, V., Liu, Z. G., Bennett, B., Suzuki, N., Xia, Y. and Karin,
M. (1999) Signaling by proinflammatory cytokines: oligomerization of TRAF2 and TRAF6 is sufficient for JNK and IKK activation and target gene induction via an aminoterminal effector domain. Genes Dev. 13, 1297-1308.

Choi, S., Yu, E., Lee, Y. S. and Yoo, Y. S. (2000) Involvement of cytosolic phospholipase A2 in nerve growth factor-mediated neurite outgrowth of PC12 cells. J. Biochem. Mol. Biol. 33, 525-530.

Cuenda, A., Rouse, J., Doza, Y. N., Meier, R., Cohen, P., Gallagher, T. F., Young, P. R. and Lee, J. C. (1995) SB 203580 is a specific inhibitor of a MAP kinase homologue which is stimulated by cellular stresses and interleukin-1. FEBS Lett. 364, 229-233.

Dennis, E. A. (1997) The growing phospholipase A2 superfamily of signal transduction enzymes. Trends. Biochem. Sci. 22, 1-2.

Dennis, W. C. (2001) Excitotoxicity, apoptosis, and ischemic stroke. J. Biochem. Mol. Biol. 34, 8-14.

Feuerstein, G., Wang, X. and Barone F. C. (1998) Cytokines in brain ischemia--the role of TNF alpha. Cell Mol. Neurobiol. 18, 695-701.

Fiore, M., Probert, L., Kollias, G., Akassoglou, K., Alleva, E. and Aloe, L. (1996) Neurobehavioral alterations in developing transgenic mice expressing TNF- $\alpha$ in the brain. Brain Behav. Immun. 10, 126-138.

Gendron, R. L., Nestel, F. P., Lapp, W. S. and Baines, M. G. (1991) Expression of tumor necrosis factor alpha in the developing nervous system. Int. J. Neurosci. 60, 129-136.

Greene, L. A. (1982) PC12 pheochromocytoma cultures in neurobiological research. Adv. Cell. Neurobiol. 3, 373-414.

Greene, L. A. and Tischler, A. S. (1976) Establishment of a noradrenergic clonal line of rat adrenal pheochromocytoma cells which respond to nerve growth factor. Proc. Natl. Acad. Sci. USA 73, 2424-2428

Harada, J. and Sugimoto, M. (1999) An inhibitor of p38 and JNK MAP kinases prevents activation of caspase and apoptosis of cultured cerebellar granule neurons. Jpn. J. Pharmacol. 79, 369-378.

Hii, C. S., Huang, Z. H., Bilney, A., Costabile, M., Murray, A. W., Rathjen, D. A., Der, C. J. and Ferrante, A. (1998) Stimulation of $\mathrm{p} 38$ phosphorylation and activity by arachidonic acid in HeLa cells, HL60 promyelocytic leukemic cells, and human neutrophils. Evidence for cell type-specific activation of mitogen-activated protein kinases. J. Biol. Chem. 273, 1927719282.

Ichijo, H., Nishida, E., Irie, K., ten, Dijke, P., Saitoh, M., Moriguchi, T., Takagi, M., Matsumoto, K., Miyazono, K. and Gotoh, Y. (1997) Induction of apoptosis by ASK1, a mammalian MAPKKK that activates SAPK/JNK and p38 signaling pathways. Science 275, 90-94.

Jarskog, L. F., Xiao, H., Wilkie, M. B., Lauder, J. M. and Gilmore, J. H. (1997) Cytokine regulation of embryonic rat dopamine and serotonin neuronal survival in vitro. Int. J. Dev. Neurosci. 15, 711-716.

Jun, C. D., Pae, H. O., Kwak, H. J., Yoo, J. C., Choi, B. M., Oh, C. D., Chun, J. S., Paik, S. G., Park, Y. H. and Chung, H. T. (1999) Modulation of nitric oxide-induced apoptotic death of HL-60 cells by protein kinase C and protein kinase A through mitogen-activated protein kinases and CPP32-like protease pathways. Cell Immunol. 194, 36-46.

Katsuki, H. and Okuda, S. (1995) Arachidonic acid as a 
neurotoxic and neurotrophic substance, Prog. Neurobiol. 46, 607-636.

Kim, S. N., Park, J. -G., Bea, E., Kim, S. S. and Yoo, Y. S. (2000) Characterization of epidermal growth factor receptor function in lysophosphatidic acid signaling in PC 12 cells. $J$. Cell. Biochem. 76, 386-393.

Knoblach, S. M., Fan, L. and Faden, A. I. (1999) Early neuronal expression of tumor necrosis factor-alpha after experimental brain injury contributes to neurological impairment. $J$. Neuroimmunol. 95, 115-125.

Koh, H.-J., Park, H.-H. and Lee, C.-E. (2000) Regulation of IgE and type II IgE receptor expression by insulin-like growth factor of STAT6 and NFkB. J. Biochem. Mol. Biol. 33, 454462.

Lafortune, L., Nalbantoglu, J. and Antel, J. P. (1996) Expression of tumor necrosis factor alpha (TNF alpha) and interleukin 6 (IL-6) mRNA in adult human astrocytes: comparison with adult microglia and fetal astrocytes. J. Neuropathol. Exp. Neurol. 55, 515-521.

Lee, J. C. and Young, P. R., (1996) Role of CSB/p38/RK stress response kinase in LPS and cytokine signaling mechanisms. $J$. Leukoc. Biol. 59, 152-157.

Lee, J. C., Laydon, J. T., McDonnell, P. C., Gallagher, T. F., Kumar, S., Green, D., McNulty, D., Blumenthal, M. J., Heys, J. R., Landvatter, S. W. (1994) A protein kinase involved in the regulation of inflammatory cytokine biosynthesis. Nature 372, 739-746.

Malinin, N. L., Boldin, M. P., Kovalenko, A. V. and Wallach, D. (1997) MAP3K-related kinase involved in NF-kappaB induction by TNF, CD95 and IL-1. Nature 385, 540-544.

Modur, V., Zimmerman, G. A., Prescott, S. M. and McIntyre, T. M. (1996) Endothelial cell inflammatory responses to tumor necrosis factor alpha. Ceramide-dependent and -independent mitogen-activated protein kinase cascades. J. Biol. Chem. 271, 13094-13102.

Pan, W., Kastin, A. J., Bell, R. L. and Olson, R. D. (1999) Upregulation of tumor necrosis factor alpha transport across the blood-brain barrier after acute compressive spinal cord injury. $J$. Neurosci. 19, 3649-3655.

Park, J. -G., Jo, Y., Kim, Y. T. and Yoo, Y. S. (1998) Requirement of EGF receptor kinase for signaling by calcium-induced ERK activation and neurite outgrowth in PC12 cells. J. Biochem. Mol. Biol. 31, 468-474.

Probert, L., Akassoglou, K., Kassiotis, G., Pasparakis, M., Alexopoulou, L. and Kollias, G. (1997) TNF-alpha transgenic and knockout models of CNS inflammation and degeneration. J. Neuroimmunol. 72, 137-144.

Roulston, A., Reinhard, C., Amiri, P. and Williams, L. T. (1998) Early activation of c-Jun N-terminal kinase and p38 kinase regulate cell survival in response to tumor necrosis factor alpha. J. Biol. Chem. 24, 10232-10239.

Shafer, T. J. and Atchison, W. D. (1991) Transmitter, ion channel and receptor properties of pheochromocytoma (PC12) cells: a model for neurotoxicological studies. Neurotoxicology 12, 473492.

Street, I. P., Lin, H. K., Laliberte, F., Ghomashchi, F., Wang, Z., Perrier, H., Tremblay, N. M., Huang, Z., Weech, P. K. and Gelb, M. H. (1993) Slow- and tight-binding inhibitors of the 85-kDa human phospholipase A2. Biochemistry 32, 5935-5940.

Tamatani, M., Che, Y. H., Matsuzaki, H., Ogawa, S., Okado, H., Miyake, S., Mizuno, T. and Tohyama, M. (1999) Tumor necrosis factor induces $\mathrm{Bcl}-2$ and $\mathrm{Bcl}-\mathrm{x}$ expression through NFkappaB activation in primary hippocampal neurons. J. Biol. Chem. 274, 8531-8538.

Tchelingerian, J. L., Le Saux, F. and Jacque, C., Identification and topography of neuronal cell populations expressing TNF alpha and IL-1 alpha in response to hippocampal lesion. J. Neurosci. Res. 43, 99-106.

Wissing, D., Mouritzen, H., Egeblad, M., Poirier, G. G. and Jaattela, M. (1997) Involvement of caspase-dependent activation of cytosolic phospholipase A2 in tumor necrosis factor-induced apoptosis. Proc. Natl. Acad. Sci. USA 94, 5073-5077.

Yuasa, T., Ohno, S., Kehrl, J. H. and Kyriakis, J. M. (1998) Tumor necrosis factor signaling to stress-activated protein kinase (SAPK)/Jun NH2-terminal kinase (JNK) and p38. Germinal center kinase couples TRAF2 to mitogen-activated protein kinase/ERK kinase kinase 1 and SAPK while receptor interacting protein associates with a mitogen-activated protein kinase kinase kinase upstream of MKK6 and p38. J. Biol. Chem. 273, 22681-22692. 